Int. J. Electrochem. Sci., 14 (2019) 9888 - 9897

\title{
Characterization and Electrocatalytic Properties of the Phosphomolybdate-PAMAM Nanocomposite Film
}

\author{
Daolin Zhul, and Shouguo Wu' , Yijiang Shao ${ }^{1, *}$ \\ ${ }^{1}$ Department of Biotechnology, Hefei Technology College, Chaohu 238000, P. R. China \\ ${ }^{2}$ Department of chemistry, University of Science and Technology of China, Hefei, Anhui, 230026, P.R. \\ China \\ *E-mail: shaoyijiang@,126.com
}

doi: $10.20964 / 2019.10 .08$

Received: 28 February 2019/ Accepted: 2 August 2019 / Published: 30 August 2019

The phosphomolybdate-PAMAM nanocomposite film was successfully prepared by using a submonolayer of 3-mercaptopropionic acid (3-MPA) adsorbed on a polycrystalline gold electrode further reacted with poly(amidoamine) (PAMAM) dendrimer (generation 4.0) to obtain a film on which 1:12 phosphomolybdate acid (PMo12) was later coordinated to afford a mixed electrocatalytic layer. On the basis of the electrochemical behaviors, atomic force microscopy (AFM) and X-ray photoelectron spectra (XPS), it is suggested that the PMo12 nanoparticles are located within the dendritic structure of the surface attached PAMAM dendrimers. The protonated environment provided by PAMAM not only promises the higher electroactivity of $\mathrm{PMo}_{12}$ at weak acidic condition, but also improves its stability. It was illustrated experimentally that the hybrid film showed a high electrocatalytic activity for reduction of $\mathrm{S}_{2} \mathrm{O}_{8}{ }^{2-}$ and $\mathrm{H}_{2} \mathrm{O}_{2}$ in the aqueous solution of $\mathrm{pH} 4.0$.

Keywords:Phosphomolybdate acid (PMo12), PAMAM, Nanocomposite, Electrocatalysis, $\mathrm{S}_{2} \mathrm{O}_{8}{ }^{2-}, \mathrm{H}_{2} \mathrm{O}_{2}$.

\section{$\underline{\text { FULL TEXT }}$}

(C) 2019 The Authors. Published by ESG (www.electrochemsci.org). This article is an open access article distributed under the terms and conditions of the Creative Commons Attribution license (http://creativecommons.org/licenses/by/4.0/). 